\title{
Research on Alignment Consistency of Highways with the Basis of $85 \mathrm{MSR}$
}

\author{
Xinglei Zhang ${ }^{1, ~ a, ~ X i a n g h a i ~ M e n g ~}{ }^{2, b}$ \\ ${ }^{1}$ School of Transportation Science and Engineering, Harbin Institute of Technology, Harbin, China \\ ${ }^{2}$ School of Transportation Science and Engineering, Harbin Institute of Technology, Harbin, China \\ a zhang_xinglei321@126.com, ${ }^{b}$ mengxianghai100@126.com
}

Keywords: traffic engineering; four-lane highways; alignment consistency; 85MSR.

\begin{abstract}
The alignment consistency of highways is an important guarantee for vehicle safety. In this thesis, by comparing the computing methods of $\Delta \mathrm{V}_{85}$ and $85 \mathrm{MSR}$, the author concludes that $85 \mathrm{MSR}$ is a more appropriate way to evaluate the highway alignment consistency. The author studies Ningfu section on Heda superhighway with 85MSR, pointing out the section with poor alignment consistency, and provides basic data for the analysis and prevention of this section and road improvement.
\end{abstract}

\section{Introduction}

Highway alignment, which dominates the planning, designing and constructing of highways, is the framework for highways. The alignment design has crucial influence on vehicle safety, comfort, economic performance, and traffic volume of highways. The alignment design includes horizontal design, longitudinal deign and combinatorial design. Criteria to measure a good design include reasonable selection of each parameter (e.g. sighting distance, superelevation, longitudinal slope and curve radius, etc.), following the principle of combinatorial design, harmony with environment and landscape along the highway so that drivers can visually see alignment consistency and mentally feel comfortable and safe[1].

\section{Analysis in Alignment Consistency of Highways}

\section{Operating Speed}

Operating speed refers to the 85th percentile speed measured on the characteristic point of a highway section when the traffic is in free flow and the weather is good [2]. The operating speed is proposed and applied in research by the United States, Germany and Australia, which ultimately reflects the smoothness and safety of horizontal and longitudinal alignment parameters.

With plenty of actual research, many countries use the operating speed as a basis for highway consistency design and adopt $\mathrm{V}_{85}$ as the operating speed to carry out alignment design so as to meet the basic requirement for coordinative dereferencing between each parameter and balanced alignment design. The followings are advantages of studying and solving highway alignment design on the basis of operating speed [3] :

(1) The blindness and non-concreteness, which is caused by using design speed as a fixed value in highway alignment design, can be avoided;

(2) The operating speed is determined from measured data and the elements for alignment design based on the operating speed can satisfy the running requirement and solve the compatibility problems between different design elements;

(3) Different factors, such as highway conditions, drivers, vehicles, natural landscape along the highways, and environment, affecting actual speed, are taken into consideration. So it is more scientific and comprehensive to study the highway alignment with operating speed;

(4) The principle of speed change control can guarantee the speed consistency on different sections without speed breakpoint so as to ensure that the highway alignment is successive. 


\section{The Traditional Evaluation Criteria for Alignment Consistency}

Research shows that if highway alignment features are in conformity with driver expectations, operational errors will be obviously less than those happen when they are not in conformity. The highway alignment parameters, such as horizontal and longitudinal curve radius, longitudinal slope, superelevation, and widening, sight distance etc., are major factors that affect the operating speed, and whether the alignment elements are successive is reflected by the success of operating speed, so it is quite reliable to analyze the highway alignment condition with operating speed. The alignment consistency on a certain highway section can be analyzed by reasonable section division and measured actual operating speed.

Evaluation criteria for alignment consistency are of vital importance. Opposite conclusions may be reached if the alignment design quality on the same highway is evaluated with different criteria. And the same criterial is not applicable to all the countries due to different national conditions. Some countries started the alignment evaluation at early time and have made certain achievements. The USA is one of such countries; according to its research data, the operating speed difference between adjacent horizontal curve sections is closely related to safety conditions on the curve section ${ }^{[4]}$, and the specific data are shown on the following Table1.

Table1 Relevance between Variability Trend in Operating Speed and Traffic Accident Rate

\begin{tabular}{ccc}
\hline $\begin{array}{c}\text { Gradient of Operating Speed } \\
{[\mathrm{km} / \mathrm{h}]}\end{array}$ & $\begin{array}{c}\text { Total Accidents in } \\
3 \text { Years }\end{array}$ & $\begin{array}{c}\text { Accident Rate } \\
\text { [time/million vehicle kilometers] }\end{array}$ \\
\hline$\left|\Delta \mathrm{V}_{85}\right|<10$ & 1483 & 0.46 \\
\hline $10 \leq\left|\Delta \mathrm{V}_{85}\right| \leq 20$ & 217 & 1.44 \\
\hline$\left|\Delta \mathrm{V}_{85}\right|>20$ & 47 & 2.76 \\
\hline
\end{tabular}

On the basis of analyzing and tracing evaluation achievements of traffic safety made by America and European countries, and combining with the national conditions, China also deeply studies the relationships between traffic accident and highway geometrical parameters, traffic accident and operating speed, and highway geometrical parameters and operating speed. With gradual improvement of vehicle structures, size increased, power enhanced, the varibility capacity of operating speed to which vehicles can adapt is largely advanced, which calls for gradual improvement of highway alignment. But we cannot increase the operating speed by blindly improve alignment because it will result in a closed loop, so necessary traffic safety devices and legal approaches shall be supplemented. Combining research achievements of other countries and actual situation of China, $\Delta \mathrm{V} 85$, the difference between operating speed on adjacent section, is adopted as the evaluation index, and the evaluation criteria for alignment consistency provided in Instruction ${ }^{[2]}$ is employed, as shown in Table 2.

Table 2 Evaluation Criteria for Alignment Consistency

\begin{tabular}{cc}
\hline $\begin{array}{c}\text { Operating Speed Difference } \\
{[\mathrm{km} / \mathrm{h}]}\end{array}$ & Alignment Consistency \\
\hline$\left|\Delta \mathrm{V}_{85}\right|<10$ & Excellent \\
\hline $10 \leq\left|\Delta \mathrm{V}_{85}\right| \leq 20$ & Good \\
\hline$\left|\Delta \mathrm{V}_{85}\right|>20$ & Poor \\
\hline
\end{tabular}

\section{The Proposition of 85MSR}

According to the traditional calculating method of $\Delta \mathrm{V}_{85}$, speeds on two adjacent sections are supposed to be mutually independent, while the mutual influence of speeds on front and back alignments are not considered. The following Fig. 1 shows the speed variability when a vehicle runs on adjacent sections. 

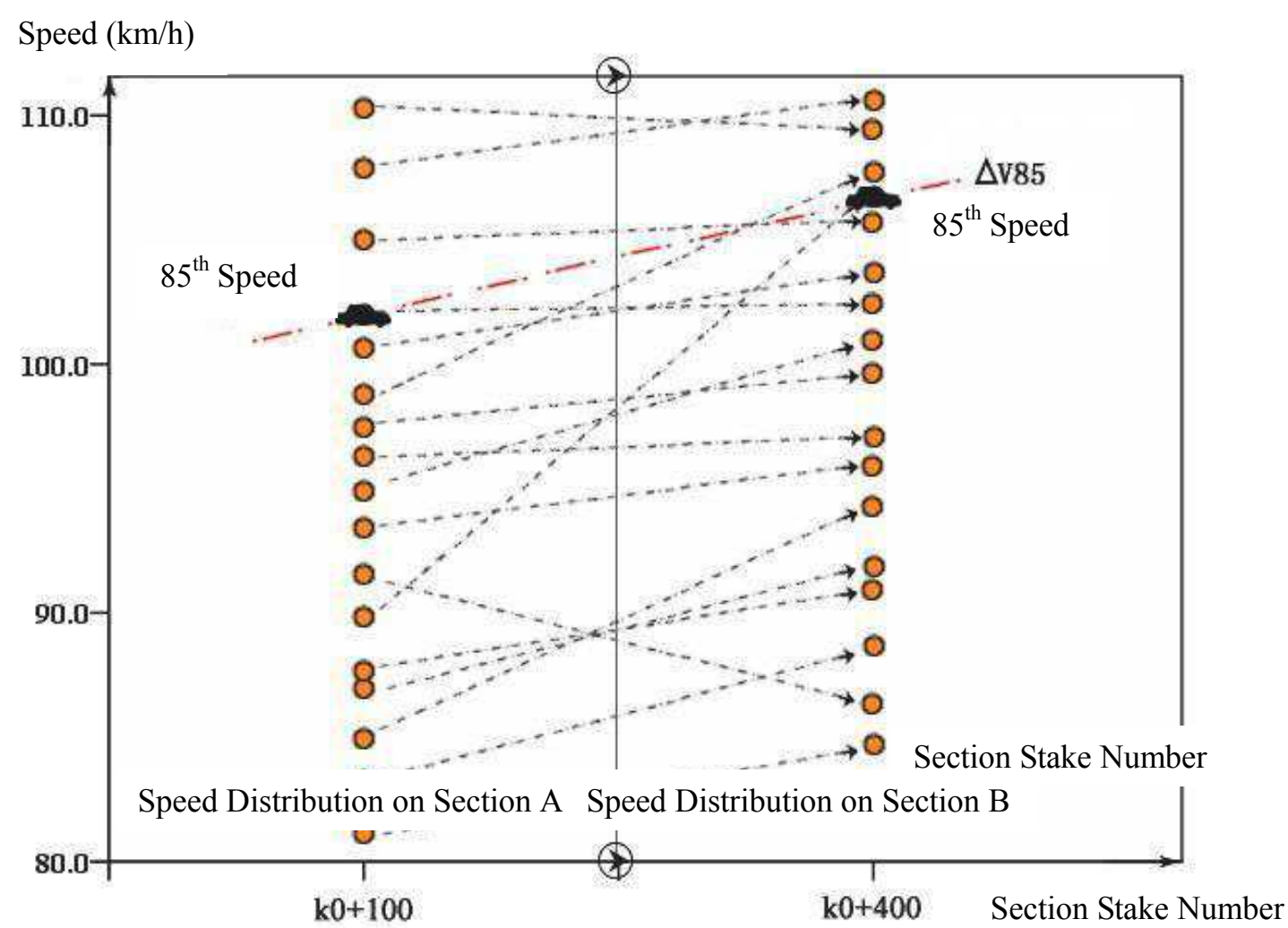

Speed Distribution on Section A Speed Distribution on Section B

Fig. 1 Operating Speed Variability on Adjacent Sections

It can be seen from the above diagram that only the corresponding relation between two independent individuals is considered, which does not conform to actual situation because vehicle speed is not only related to gender, age, and driving behavior of a driver but also influenced by other vehicles in the process of running.

Because of the above consideration, speed difference of individual vehicles on adjacent sections shall be calculated separately, and then the value on $85 \%$ shall be obtained, so as to define as $85 \mathrm{MSR}$.

This method takes the mutual influence of speeds on front and back alignments into consideration and eliminates the shortcoming of $\Delta \mathrm{V}_{85}$ to a great extent, and the next step is to study the specific relationship between $85 \mathrm{MSR}$ and $\Delta \mathrm{V}_{85}$ with mathematical methods $[5,6]$.

It can be known from the calculation methods that $\Delta V_{85}$ studies the relationship between two individuals while 85MSR studies the group relationship, and $\Delta \mathrm{V}_{85}$ assumes that speeds on front and back sections has no influence on each other while $85 \mathrm{MSR}$ takes the mutual influence into consideration.

The following is the calculation formula of $\Delta \mathrm{V}_{85}[6]$ :

$$
\Delta V_{85}=V_{(i) 85}-V_{(i-1) 85}=\overline{V_{1}}-\overline{V_{2}}+Z_{|85|}\left(\sigma_{1}-\sigma_{2}\right)
$$

Where, $\bar{V}_{1}, \overline{V_{2}}$ are Average speed on front and back sections; $\sigma_{1}, \sigma_{2}$ are Standard difference of speed on front and back sections; $Z_{|85|}$ is $85^{\text {th }}$ value on standard normal analysis.

When mutual influence of speeds on front and back sections are considered, calculation formula of 85MSR is as follows[6]:

$$
\begin{gathered}
85 M S R=\left(V_{1}-V_{2}\right)_{|85|}=\left(\overline{V_{1}}-\overline{V_{2}}\right)+Z_{|85|} \sqrt{\sigma_{1}^{2}+\sigma_{2}^{2}-2 \operatorname{cov}\left(V_{1}, V_{2}\right)} \\
\operatorname{Var}\left(V_{1}-V_{2}\right)=\sigma_{1}^{2}+\sigma_{2}^{2}-2 \operatorname{cov}\left(V_{1}, V_{2}\right)
\end{gathered}
$$


Where, $\operatorname{cov}\left(V_{1}, V_{2}\right)$ is Covariance.

Suppose correlation coefficient of $V_{1}, V_{2}$ as $\rho=\frac{\operatorname{cov}\left(V_{1}, V_{2}\right)}{\sigma_{1} \sigma_{2}}$, on the basis of its quality, there is:

$$
\left|\frac{\operatorname{cov}\left(V_{1}, V_{2}\right)}{\sigma_{1} \sigma_{2}}\right| \leq 1 \text { or }-\sigma_{1} \sigma_{2} \leq \operatorname{cov}\left(V_{1}, V_{2}\right) \leq \sigma_{1} \sigma_{2}
$$

So the following relation always establishes:

$$
\sqrt{\sigma_{1}^{2}+\sigma_{2}^{2}-2 \operatorname{cov}\left(V_{1}, V_{2}\right)} \geq\left(\sigma_{1}-\sigma_{2}\right)
$$

Namely, $85 \mathrm{MSR} \geq \Delta \mathrm{V}_{85}$ always establishes, so the alignment consistency may be overestimated when it is evaluated with $\Delta \mathrm{V}_{85}$ and the effect is not as good as $85 \mathrm{MSR}$, so this thesis adopts $85 \mathrm{MSR}$.

\section{Analysis of Project Case}

\section{General Situation of the Inspected Section}

All the data in this thesis come from the project named Evaluation of Alignment Adaptability and Research on Improvement Measures after First-Class Highway Becomes Superhighway supported by Department of Transport of Heilongjiang Province. Ningfu Section (at the border of Heilongjiang and Jilin) on Heda Superhighway is selected for the research, the design speed is $80 \mathrm{~km} / \mathrm{h}$, and it is a dual four-lane highway with the roadbed width of $24.5 \mathrm{~m}$. The researched highway is on mountainous areas with complicated topography. 8 typical sections are selected from the project data; among them, some have certain evident single alignment parameter, e.g. high gradient value of small radius and some are sections with combination of horizontal and longitudinal features, which has great values for comparative analysis and are convenient for targeted research.

\section{Data Analysis}

In this thesis, $\mathrm{V}_{85}$ value is also used as the operating speed when analyzing the relationship between alignment and speed. The $\mathrm{V}_{85}$ value is from statistic method; the $\mathrm{V}_{85}$ value of each section can be obtained from curve chart for accumulated frequency distribution of speed. Please refer to Table 3.

Table $3 \mathrm{~V}_{85}$ Value of Oversize Vehicles on Researched Sections

\begin{tabular}{cccc}
\hline $\begin{array}{c}\text { Section Mileage } \\
\text { Stake Number }\end{array}$ & $\begin{array}{c}\mathrm{V}_{85} \\
{[\mathrm{~km} / \mathrm{h}]}\end{array}$ & $\begin{array}{c}\text { Section Mileage } \\
\text { take Number }\end{array}$ & $\begin{array}{c}\mathrm{V}_{85} \\
{[\mathrm{~km} / \mathrm{h}]}\end{array}$ \\
\hline $\mathrm{k} 1+300 \sim \mathrm{k} 1+400$ & 79.57 & $\mathrm{k} 22+900 \sim \mathrm{k} 23+100$ & 72.50 \\
\hline $\mathrm{k} 1+400 \sim \mathrm{k} 1+500$ & 83.11 & $\mathrm{k} 26+600 \sim \mathrm{k} 26+700$ & 59.34 \\
\hline $\mathrm{k} 1+500 \sim \mathrm{k} 1+600$ & 68.93 & $\mathrm{k} 26+700 \sim \mathrm{k} 26+800$ & 64.64 \\
\hline $\mathrm{k} 7+700 \sim \mathrm{k} 8+000$ & 92.33 & $\mathrm{k} 27+200 \sim \mathrm{k} 27+400$ & 82.00 \\
\hline $\mathrm{k} 8+000 \sim \mathrm{k} 8+100$ & 50.94 & $\mathrm{k} 27+400 \sim \mathrm{k} 27+600$ & 77.15 \\
\hline $\mathrm{k} 8+100 \sim \mathrm{k} 8+200$ & 50.63 & $\mathrm{k} 27+600 \sim \mathrm{k} 27+800$ & 81.61 \\
\hline $\mathrm{k} 8+200 \sim \mathrm{k} 8+300$ & 51.42 & $\mathrm{k} 30+100 \sim \mathrm{k} 30+300$ & 99.41 \\
\hline $\mathrm{k} 15+200 \sim \mathrm{k} 15+400$ & 73.66 & $\mathrm{k} 30+300 \sim \mathrm{k} 30+500$ & 101.66 \\
\hline $\mathrm{k} 15+400 \sim \mathrm{k} 15+600$ & 68.76 & $\mathrm{k} 30+500 \sim \mathrm{k} 30+700$ & 92.60 \\
\hline $\mathrm{k} 15+600 \sim \mathrm{k} 15+700$ & 59.07 & $\mathrm{k} 30+700 \sim \mathrm{k} 30+900$ & 77.53 \\
\hline $\mathrm{k} 22+500 \sim \mathrm{k} 22+700$ & 99.70 & $\mathrm{k} 39+700 \sim \mathrm{k} 40+000$ & 84.36 \\
\hline $\mathrm{k} 22+700 \sim \mathrm{k} 22+900$ & 92.81 & $\mathrm{~K} 40+000 \sim \mathrm{k} 40+400$ & 86.69 \\
\hline
\end{tabular}

The $\Delta V_{85}$ value on each section can be figured out according to the above operating speed, but the $85 \mathrm{MSR}$ value cannot be figured out. According to the formula [7]:

$$
85 M S R=2.171 \Delta V_{85}+4.0469
$$


Please refer to Table 4 for specific values:

Table 4 Corresponding Relation of $\Delta \mathrm{V}_{85}$ and 85MSR on Each Section

\begin{tabular}{|c|c|c|c|c|c|}
\hline $\begin{array}{c}\text { Section Stake } \\
\text { Number }\end{array}$ & $\Delta \mathrm{V}_{85}$ & 85MSR & $\begin{array}{c}\text { Section Stake } \\
\text { Number }\end{array}$ & $\Delta \mathrm{V}_{85}$ & 85MSR \\
\hline \multirow{2}{*}{$\mathrm{K} 1+300 \sim \mathrm{k} 1+600$} & 3.54 & 11.73 & \multirow{2}{*}{$\mathrm{k} 22+500 \sim \mathrm{k} 23+100$} & 6.89 & 19.01 \\
\hline & 14.18 & 34.83 & & 20.31 & 48.14 \\
\hline \multirow{3}{*}{$\mathrm{k} 7+700 \sim \mathrm{k} 8+300$} & 41.39 & 93.90 & \multirow{2}{*}{$\mathrm{k} 27+200 \sim \mathrm{k} 27+800$} & 4.85 & 14.58 \\
\hline & 0.31 & 4.72 & & 3.46 & 11.56 \\
\hline & 0.79 & 5.76 & \multirow{3}{*}{$\mathrm{k} 30+000 \sim \mathrm{k} 30+900$} & 2.25 & 8.93 \\
\hline \multirow{2}{*}{$\mathrm{k} 15+200 \sim \mathrm{k} 15+700$} & 4.90 & 14.68 & & 9.06 & 23.72 \\
\hline & 9.69 & 25.83 & & 15.07 & 36.76 \\
\hline $\mathrm{k} 26+600 \sim \mathrm{k} 26+800$ & 5.30 & 15.55 & $\mathrm{k} 39+700 \sim \mathrm{k} 40+400$ & 2.63 & 9.76 \\
\hline
\end{tabular}

\section{Evaluation of Alignment Consistency on Researched Sections}

When researching the alignment consistency of the section from Xingshan to Fuxing on Heda Superhighway, this thesis mainly calculates and analyzes the operating speed coordination of large van and states the sections with the $85 \mathrm{MSR}$ value larger than $20 \mathrm{~km} / \mathrm{h}$. According to Table $3-2$, the $85 \mathrm{MSR}$ of the sections of $\mathrm{K} 1+400 \sim \mathrm{k} 1+600, \mathrm{k} 7+700 \sim \mathrm{k} 8+100, \mathrm{k} 15+400 \sim \mathrm{k} 15+700$, $\mathrm{k} 22+700 \sim \mathrm{k} 23+100, \mathrm{k} 30+300 \sim \mathrm{k} 30+700$ and adjacent section of $\mathrm{k} 30+500 \sim \mathrm{k} 30+900$ are larger than $20 \mathrm{~km} / \mathrm{h}$, and the alignment consistency of adjacent sections is poor.

\section{Summary}

The safe highway alignment design does not lie in horizontal or longitudinal qualifications of the whole line (or part of it), but in the consistency and balance of the entire alignment. Analyzing the alignment consistency with the combination of alignment parameters and operating speed can effectively overcome the disadvantage of design speed and guarantee the continuity and consistency when vehicles running on successive sections. Traditional $\Delta \mathrm{V}_{85}$ does not sufficiently consider the operating speed of individual vehicle, so this thesis adopts the method of 85MSR and studies the alignment consistency of the section from Xingshan to Fuxing on Heda Superhighway, and then finds out the sections with poor alignment consistency and provides basic data for the analysis of traffic safety factors and road improvement.

\section{References}

[1] JTG D20-2006, Design Specifications for Highway Route[S].

[2] JTG/T B05 - 2004.Instruction for Safety Instruction of Highway Project [S].Beijing: China Communications Press.2004.10.

[3] Wang Heng, Fang Shou'en. Operating Speed Calculation with Consideration of Accelerated Speed [J].Shandong Transport Science. 2004.3:10 12.

[4] Liu Yuntong. Instruction for Road Traffic Safety [M].Beijing: China Communications Press.2004.7.

[5] McFadden J, Elefteriadou L. Evaluating horizontal alignment design consistency of two-lane rural highways: Development of new procedure [J]. Transportation Research Record 1737, Washington D. C., $9-17,2000$.

[6] Young-Jin Park, Frank F. Saccomanno. Evaluating speed consistency between successive elements of a two-lane rural highway [J]. Transportation Research Part A 40 (2006) 375-385.

[7] Liu Zhiqiang, Wang Yunxia, Huang Cheng. Method Study of Highway Alignment Continuity Based on 85MSR [J]. Highway Transport Science. 2008.6:36 38. 